\title{
PCA Esaslı Hibrit ANFIS-Taguchi Yöntemi ile Kan Bankası için Talep Tahmini Araştırma Makalesi/Research Article
}

\author{
Seda Hatice GÖKLER ${ }^{1}$, (D) Semra BORAN ${ }^{2}$ \\ ${ }^{1}$ Endüstri Mühendisliği Bölümü, Mühendislik Fakültesi, Sakarya, Türkiye \\ ${ }^{2}$ Endüstri Mühendisliği Bölümü, Mühendislik Fakültesi, Sakarya, Türkiye \\ shgokler@sakarya.edu.tr, boran@sakarya.edu.tr \\ (Geliş/Received:21.06.2019; Kabul/Accepted:07.06.2020) \\ DOI: $10.17671 /$ gazibtd. 580530
}

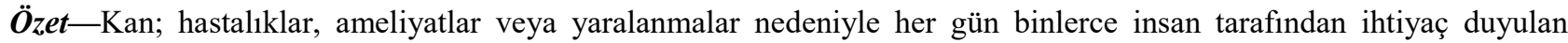
hayati bir üründür. Bu nedenle hastanelerin kan ihtiyacını karşılayan kan bankalarının stoklarında yeterli miktarda kan bulundurması gereklidir. Gereğinden az miktarda kan elde bulundurulması ihtiyacın karşılanamaması ve can kaybı gibi önemli sorunlar oluştururken, fazla miktarda kanın stoklanması ise kanın bozulmasına ve kan ihtiyacı olan farklı hastanelerin stoksuz kalmasına neden olmaktadır.

Bu çalışmada öncelikle kan bileşenlerinden biri olan eritrosit süspansiyonu talebine etki eden kriterler belirlenerek; bu kriterlere göre makine öğrenme algoritmalarından uyarlamalı ağ tabanlı bulanık çıkarım sistemi (ANFIS) yöntemi ile talebin tahmin edilmesi amaçlanmaktadır. Ancak talebe etki eden çok sayıda kriter olduğu için gruplandırarak azaltmak ve kriterler arasındaki bağımlılıkları ortadan kaldırmak amacıyla temel bileşen analizi (PCA) yönteminden yararlanılmıştır. Ayrıca ANFIS'in performansı; modelin yapısı ve öğrenmesini etkileyen parametre değerlerinin doğru belirlenmesi ile ilişkili olduğundan en yüksek doğrulukla tahmini sağlayacak değerler Taguchi deney tasarımı yöntemiyle belirlenmiştir. Geliştirilen PCA esaslı hibrit ANFIS-Taguchi yöntemi bir bölge kan merkezinde uygulanmıştır. Korelasyon katsayısı $(R)$ performans ölçütü ile yöntemin tahmin yeteneği değerlendirilmiştir. Uygulama sonunda tahmin edilen eritrosit süspansiyon talep miktarının \%88.1 oranla gerçekleşen talep miktarı ile benzer sonuç verdiği görülmüştür.
\end{abstract}

Anahtar Kelimeler-ANFIS, PCA, taguchi metodu, talep tahmini

\section{Hybrid ANFIS-Taguchi Method Based on PCA for Blood Bank Demand Forecasting}

\begin{abstract}
Blood is a vital product that is needed by thousands of people every day due to diseases, surgeries or injuries. For this reason, it is necessary that the blood banks have enough blood quantity to meet the blood needs of hospitals . The provision of small amounts of blood in hospitals creates significant problems such as loss of life and can't meet the demand. On the other hand, the stocking of large amounts of blood leads to the wastage of blood and the stockless of blood different hospitals.

The aim of this study is to determine the criteria affecting blood demand and to forecast the blood demand by the machine learning algorithm Adaptive Network Based Fuzzy Inference System (ANFIS) method. However, since the number of impact criteria is high, principal component analysis (PCA) method has been used in order to decrease criteria and eliminate the dependencies between the criteria. In addition, the performance of ANFIS depend on determining ANFIS parameters that affect its structure and learning. So to provide the highest learning ANFIS parameters were determined by the Taguchi experimental design method. The developed hybrid method was applied in a regional blood center and evaluated with correlation coefficient $(R)$. At the end of the application, it is seen that the estimated red blood cells demand is similar to the demand amount realized at the rate of $88.1 \%$.
\end{abstract}

Keywords - ANFIS, PCA, taguchi method, demand forecasting 


\section{GİRIŞ (INTRODUCTION)}

Hastalıklar, ameliyatlar veya yaralanmalar nedeniyle her gün binlerce insan kan nakline ihtiyaç duymaktadır. Güvenli kan ihtiyacının karşılanması sorumluluğu 'Sağlıkta Dönüşüm Programı' kapsamında Türk Kızılay'ına verilmiştir. Kızılay kanının toplanması, test edilmesi, işlenip kan bileşeni haline getirilmesi ve transfüzyon merkezlerine transfer edilmesini sağlamaktadır.

Türk Kızılay’ı bu kan bankacığı faaliyetlerini 3 ana birimde yürütmektedir. Bunlar; kan bağış merkezleri, bölge kan merkezleri (BKM) ve transfüzyon merkezleri (TM)'dir. Kan bağış merkezleri gönüllü bağışçılardan kan bağışı kabul etmektedir. Toplanan kan bağışları depolanmak ve işlenmek üzere BKM'lere getirilmektedir. Testler sonucunda uygun olduğu anlaşılan kan bileşenleri karantinadan çıkarılıp 3 adet kan bileşenine ayrılarak talep edilen miktarlar doğrultusunda TM'lere gönderilir. Söz konusu olan kan bileşenleri eritrosit süspansiyonu, trombosit süspansiyonu ve taze donmuş plazmadır.

Kan bankacılığında kan bileşenlerine ait talep miktarlarının doğru tahmin edilmesi önemli bir sorundur. Tahmin edilen kan bileşeni miktarı TM'nin talep edeceği miktardan fazla olursa; kan bileşeninin stokta miadının dolması söz konusu olabilir. Dolayısıyla kan bileşeninin imha edilmesi gerekmektedir. İmha edilen kan bileşeni BKM'ye olan güvenin azalmasina neden olur. Bunun yanı sıra imha edilen kan bileşenlerinin depolanması, test edilmesi, işlenmesi ve taşınması gibi maliyetlere katlanılmak zorunda kalınır. Ayrıca imha edilen kan bileşenlerinin başka bir TM'de diğer hastaya nakledilmesi imkânsız hale gelir. Bunun tam tersi durumda tahmin edilen kan bileşeni miktarı TM'nin talep edeceği miktardan az olmasıdır. Bu durumda TM'de kan bileşeni talebinin karşılanamaması nedeniyle diğer BKM'den kan istenmesi veya TM'nin kan bağışı kabul etmesi gerekmektedir. Böylece yaşanacak gecikmeler can kaybı gibi önemli sonuçlara yol açabilecektir.

Literatürde kan bileşenlerinin talep miktarının tahmin edilmesini esas alan birkaç çalışma yer almaktadır. Bu çalışmalardan biri Akita vd. tarafından yapılmıştır. Çalışmada, Japonya'nın kan arzını ve talebini yaş ve cinsiyet kriterlerine göre tahmin eden bir Markov modeli geliştirilmiştir [1]. Lau vd. ise kan talebinin yaş, cinsiyet, vücut ağırlığı, transfüzyon yılı ve splenektomi ile potansiyel ilişkilerini kurmak için uygun genelleştirilmiş matematiksel tahmin modeli oluşturmuşlardır [2]. Currie vd demografik değişikliklerin gelecek 25 yıldaki kan talep ve arzındaki etkisini incelemişlerdir [3]. Kumari ve Wijayanayake trombosit kan bileşeninin yoksatmasını en aza indirecek ağırlıklı hareketli ortalama, hareketli ortalama ve üstel düzleştirme tahmin yöntemlerinden yararlanmışlardır [4]. Yine Wijayanayake ve Dandunna çalışmalarında trombosit bileşeninin talep tahmini için matematiksel model oluşturmuşlardır [5].
Ele aldığımız kan bileşeni olan eritrosit süspansiyonu talebinin tahminini esas alan çalışmalar da vardır. Drackley vd, yaşa ve cinsiyete bağlı bağış ve talep oranlarını hesaplayan ve 28 yıllık eritrosit süspansiyonu talebini öngören bir model geliştirmişlerdir [6]. Pereira ise eritrosit süspansiyonu için tek değişkenli zaman serisi metodu kullanarak aylık talep tahmininde bulunmuştur [7].

Görüldüğü gibi literatürde çoğunlukla yaş, kan grubu, cinsiyet gibi değişkenler kullanılarak zamana bağlı olarak değişen niceliksel tahmin yöntemleri ve simülasyon yöntemi kullanılmıştır. Ancak kan bileşeni talep miktarı dış dünyadan oldukça fazla etkilenmektedir ve sürekli değişkenlik göstermektedir. Kan bileşeni talebini ve bağışını etkileyen bazı durumlar;

a. Kanın acil ve hayatî bir ihtiyaç olması,

b. Talep miktarının belirsiz olması,

c. Talep zamanının belirsiz olması,

d. Bağış miktarının belirsiz olması,

e. Bağış zamanının belirsiz olması,

f. Hazırlanmasının zaman alıcı olması,

g. Depolama süresinin kısa olması,

h. Depolama alanının özel şartlar gerektirmesi,

i. Depolama maliyetinin yüksek olması,

j. Alınan kanın işlenme süresinin dış etkenlerden etkilendiği için belirsiz olması,

k. Kan gruplama sistemine bağlı olarak farklı kan gruplarının olmas1,

1. Bazı kan bileşeni ihtiyaçlarının özel durumlar nedeniyle eski kandan değil, taze kandan karşılanması gerekliliğidir. Örneğin prematüre bir bebeğe verilecek kan bileşeni en son bağışlanan uygun kan bağışçısının kanından seçilmelidir.

Kan bankası stok yönetiminde; belirsizliğin çok fazla olduğu ve stoğu etkileyen parametre değerleri önceden kesin olarak bilinemeyip olasılıklar çerçevesinde talep tahmin yapılabildiği için niceliksel tahmin yöntemleri yeterli olmamaktadır. Bu nedenle bazı çalışmalarda yapay sinir ağı (YSA) yöntemini kullanarak kan bileşenlerinin talep miktarını tahmin edilmeye çalışılmıştır. Firouzi vd., YSA ve ARIMA yöntemlerini kullanarak İran'da kan trombosit talebini tahmin etmeyi amaçlamışlardır [8]. Walczak ve Scharf, sipariş edilen kan miktarının hastaneye ve hastalara maliyetlerini tahmin etmek için YSA'yı kullanmışlardır [9]. Ho ve Chang, akut miyeloblastik lösemi hastaları için trombosit transfüzyon gereksinimlerini tahmin etmede YSA yöntemi ile genetik algoritma (GA) yöntemini birleştiren bir model geliştirmişlerdir [10]. Haghani vd., donörlerin kan bağış sayısını YSA ve niceliksel tahmin modelleri ile tahmin edip sonuçların karşılaştırmasını yapmışlardır. [11]. Shih ve Rajendran da zaman serileri ile YSA ve çoklu regresyon yöntemleri gibi makine öğrenme algoritmalarını kullanarak Tayvan'da faaliyet gösteren kan bankaları için tahmin çalışması yapmışlardır [12]. 
Bu çalışmada ise literatürden farklı olarak; önemli bir kan bileşeni olan eritrosit süspansiyonu talep miktarının makine öğrenme algoritması olan ANFIS ile tahmin edilmesi amaçlanmaktadır. Yapılan kısıtlı literatür araştırmasına göre kan bileşeni tahmininde ANFIS'in kullanıldığı bir çalışmaya rastlanılmamıştır ancak ANFIS yöntemi YSA ile karşılaştırıldığında, ANFIS yönteminin daha fazla avantajının olduğu söylenebilir [13-14]. ANFIS yöntemi, kendi kurallarını oluşturduğu için model YSA'dan daha kolay oluşturulabilir, yeterli uzman bilgisi olmadan eğitilebilir, daha az ezberleme hatasına neden olur, hızlı öğrenme kapasitesine ve uyum yeteneğine sahiptir. Ayrıca literatürde, ANFIS'in YSA'dan daha iyi tahmin yeteneğine sahip olduğunu gösteren birçok çalışma vardır [15-16]

Bunun yanı sıra literatürdeki kan bileşeni talep tahmin modellerinde çoğunlukla yaş, kan grubu ve cinsiyet gibi insan biyolojisi ile ilgili kriterler kullanılmıştır. Bu çalışmada ise hastane özellikleri ve çevresel faktörler gibi kriterler esas alınmıştır. Belirlenen çok sayıda kriter sayısını azaltmak için PCA yönteminden yararlanılmıştır ve talep tahmini yapabilmek için ANFIS yöntemi kullanılmıştır. ANFIS modelinin yapısal ve öğrenmesi ile ilgili en uygun parametre değerlerinin belirlenerek ögrenme performansının arttırılması amacıyla da Taguchi yönteminden yararlanılmıştır.

\section{KULLANILAN YÖNTEMLER (METHODS)}

\subsection{Temel Bileşen Analizi (Principal Compenent Analysis)}

Modelde kullanılacak bağımsız değişkenler arasında çoklu doğrusal bağlantı sorunu olduğunda veya boyutlar azaltılmak istendiğinde temel bileşen analizi (PCA) yöntemi kullanılmaktadır. PCA yöntemi en güçlü çoklu istatistiksel metotlardan biridir [17-18] ve aralarında korelasyon bulunan değişkenlerin açıkladığı yapıyı, aralarında korelasyon bulunmayan ve sayıca orijinal değişken sayısından daha az sayıda değişkenlerle ifade etme yöntemidir. Literatürde probleme etki eden değişkenlerin PCA ile ortaya konulduğu ve analiz edildiği çalışmalar vardır [19-20].

PCA yönteminin kullanılmasına neden olan çoklu doğrusal bağlantı sorunu varyans artış faktörü (VIF) ile değerlenlendirilmektedir (Eşitlik 1).

$V I F=\frac{1}{1-R^{2}}$

$\mathrm{R}^{2}$ doğrusal modelin uyumu olmak üzere, VIF değerinin 10'dan büyük olması değişkenler arasında ciddi çoklu doğrusal bağlantı sorunu olduğunu göstermektedir [21]. PCA yöntemini kullanabilmek için öncelikle iki test uygulanmalıdır. Bunlardan ilki örneklem büyüklügüüün yeterliliğini belirlemek için yapılan Kaiser-Meyer-Olkin (KMO) testidir. KMO testi değerinin 0.7 'den yüksek olması verilerin analiz için uygun olduğunu göstermektedir [22]. KMO testi değeri; $r_{i j} i$ ve $j$ kriterleri arasındaki korelasyon katsayısı ve $\mathrm{a}_{\mathrm{ij}} \mathrm{i}$ ve $\mathrm{j}$ kriterleri arasındaki kısmi korelasyon katsayısı değeri olmak üzere Eşitlik 2 yardımıyla hesaplanır.

$K M O=\frac{\sum_{J=1}^{m} \sum_{i=1}^{n} r_{i j}^{2}}{\sum_{J=1}^{m} \sum_{i=1}^{n} r_{i j}^{2}+\sum_{J=1}^{m} \sum_{i=1}^{n} a_{i j}^{2}}$

İkinci test ise bileşenler arası korelasyonu incelendiğinde düşük ilişki olmadığını ve matrisin birim matris özelliği taşımadığını gösteren Bartlett testidir. Bartlett testi sonucunda hesaplanan değerin 0.05 'den küçük olması değişkenler arasında yüksek korelasyonun olduğu ve veri setinin bileşen analizi için uygun olduğunu göstermektedir [23] (Eşitlik 3).

$X^{2}=-\left[(N-1)-\left(\frac{2 k+5}{6}\right)\right] \operatorname{In}|R|$

Eşitlikte yer alan $X^{2}$ barlett testinden elde edilen değer, $\mathrm{N}$ örneklem büyüklügüu, $\mathrm{k}$ bileşen sayısı ve $|R|$ verilerden elde edilen korelasyon matrisinin determinantıdır.

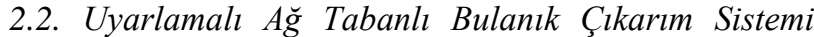 (Adaptive Network Based Fuzzy Inference System)}

Uyarlamalı ağ tabanlı bulanık çıkarım sistemi (ANFIS), Jang tarafindan geliştirilen bir sinirsel bulanık yöntemdir [24]. ANFIS yöntemi, hem sayısal hem de dilsel bilgiyi içerme özelliğine sahiptir [25]. ANFIS yöntemi, YSA'nın ve bulanık çıkarım sisteminin (BÇS) kombinasyonundan oluşmuştur ve her ikisinin olumlu özelliklerini içerir. YSA örüntü tanımlama ve sınıflandırmayı sağlarken BÇS ise modelin eğitim sürecinde geliştirilen eğer-ise kuralları ile kural tabanlı bir bulanık mantık modeli sunar. Hem geri yayılma öğrenmeyi hem de en küçük kareler yöntemini içeren karma bir öğrenme algoritmasına sahiptir. Kurallar, girdi-çıktı ilişkisini açıklayan ilgili bilgilere dayanarak formüle edilir. BÇS'nin üyelik fonksiyonu parametreleri, eğitim örneklerinden türetilir. En yaygın kullanılan BÇS'ler, Mamdani ve Sugeno tarafindan geliştirilmiş olanlardir.

Temel kural yapısı x ve y gibi iki girdi ve f gibi bir çıktı ile açıklanabilir. Sugeno modeline göre birinci dereceden eğer-ise kuralları aşağıdaki gibi tanımlanabilir (Eşitlik 4). Burada $A_{i}$ ve $B_{i}$, sırasıyla $x$ ve y girdileri için üyelik fonksiyonlarıdır ve $p_{i}, \quad q_{i}$ ve $r_{i}$ doğrusal çıktı parametreleridir. İki girdi, bir çıtı ve iki kurallı ANFIS yönteminin yapısı aşağıdaki gibidir (Şekil 1).

Kural 1: Eğer x $A_{1}$ ise ve $\mathrm{y} B_{1}$ ise, o zaman $f_{1}=p_{1 x}+q_{1 y}+r_{1}$

Kural 2: Eğer $\mathrm{x} \mathrm{A}_{2}$ ise ve $\mathrm{y}_{2}$ ise, o zaman $f_{2}=p_{2 x}+q_{2 y}+r_{2}$ 
Katman 1 Katman 2 Katman 3 Katman 4 Katman 5 Katman 6

$\mathrm{X}$

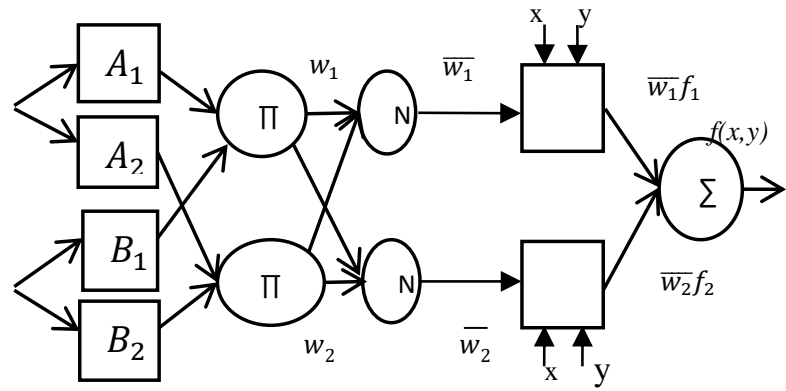

Şekil 1. ANFIS'in yapısı (ANFIS structure)

Model aynı katmandaki nöronların aynı fonksiyon ailesinden olduğu altı katman içerir. Katmanlar sırasıyla girdi (1), bulanıklaştırma (2), kural (3), normalleştirme (4), durulaştırma (5) ve çıktı katmanlarıdır (6). Katman 1. Katman tüm uyarlanabilir düğümleri içerir. Her bir düğümün girdisi üyelik fonksiyonudur ve düğüm çıktısı, O, Eşitlik 5'deki gibi hesaplanır.

$O_{1, i}=\mu_{A_{i}}(x), \quad i=1,2$

$O_{1, i}=\mu_{B_{i}-2}(y), \quad i=3,4$

Burada $\mathrm{x}$ ve $\mathrm{y}$, i düğümü için girdi, $\mathrm{A}$ ve $\mathrm{B}$ bu düğüm fonksiyonu ile ilgili düşük, orta ve yüksek gibi dilsel ifadeler ve $\mu_{A_{i}}(x)$ ve $\mu_{B_{i}-2}(y)$ üçgen, yamuk ve gauss gibi üyelik fonksiyonlarından biridir. Katman 2. Bu katmanda girdiler bulanıklaştırılır ve modelde $\pi$ olarak tanımlanır. Katman 3. Her bir kuralın ağırlık dereceleri bütün kuralların toplam ağırlık derecelerine göre değerlendirilir ve Eşitlik 6 yardımıyla kurallara ait ağırlık dereceleri hesaplanır.

$O_{2, i}=w_{i}=\mu_{A_{i}}(x) x \mu_{B_{i}}(y) \quad i=1,2$

Katman 4. Normalize etme katmanıdır. Bu katmanda her bir kural için üyelik derecesi hesaplanmaktadır (Eşitlik 7).

$O_{3, i}=\bar{w}_{i}=\frac{w_{i}}{w_{1}+w_{2}}, \quad i=1,2$

Katman 5. Her bir düğümün model çıktısına katkısı normalize edilmiş ağırlık dereceleri ile birinci dereceden polinomun çarpımıyla hesaplanır (Eşitlik 8).

$O_{4, i}=\bar{w}_{i} f_{i}=\bar{w}_{i}\left(p_{i} x+q_{i} y+r_{i}\right), \quad i=1,2$

burada $\mathrm{p}_{\mathrm{i}}, \mathrm{q}_{\mathrm{i}}$ and $\mathrm{r}_{\mathrm{i}}$ sonuç parametreleridir.

Katman 6. Modelin genel çıktısı bulunur (Eşitlik 9).

$O_{5, i}=\sum_{i} \bar{w} f_{i}=\frac{\sum_{i} w_{i} f_{i}}{\sum_{i} w_{i}}$

\subsection{Taguchi Yöntemi (Taguchi Method)}

Taguchi yöntemi, sistem parametrelerine (faktörlere) göre sistem performansını (çıktı) en iyilemeyi sağlayan basit, etkin ve en çok kullanılan deney tasarım yöntemidir [26]. Yöntemin amacı sistem performansında etkili olan faktör ve seviyelerini belirleyerek sistemin değişkenliğe karşı olan duyarlılığını azaltmaktır. Taguchi yönteminin ortogonal dizi ve sinyal-gürültü oranı gibi iki önemli aracı vardır. Ortogonal diziler deney kombinasyonlarını gösteren düzeneklerdir. Deneyler ortogonal diziye göre yapılır ve kaydedilir. Sinyal- gürültü oranı sistem performans özelliğinin istenen değerden sapmasını ölçmeyi sağlayan değişkenlik ölçüsüdür. Performans özelliğinin olması istenen durumuna göre tanımlanmış ve üç farklı sinyal-gürültü oranı en büyük en iyi, en küçük en iyi ve nominal en iyi olarak tanımlanmıştır. Bu çalışmada tahmin doğruluğu, tahmin hatası ölçütüne göre değerlendirileceği için kullanılacak en küçük en iyi sinyal gürültü oranı Eşitlik 10’daki gibidir.

$S N=-10 \log _{10}\left(\frac{1}{n} \sum_{i=1}^{n} \frac{1}{y_{i}^{2}}\right)$

Burada $y_{i}$ ölçülen i. çıktı değeri, $n$ ise deney tekrar sayısidir.

Sistem parametrelerinin performans üzerinde etkili olup olmadığını belirlemek için Varyans Analizi (Analysis of Variance-ANOVA) yöntemi uygulanır. Parametrelerin seviyeleri en büyük ortalama sinyal gürültü oranı değerine sahip olan seviye belirlenir. Böylece optimal parametre seviyeleri kombinasyonu elde edilir.

\subsection{Performans Değerlendirme Ölçütleri (Performance Evaluation Criteria)}

Çalışmada, sırasıyla Taguchi deney tasarımında test hatası olarak ortalama kare hatası (MSE); eğitilmiş modelin performansını değerlendirmek için de korelasyon katsayısı (R) performans ölçütleri kullanılmıştır (Eşitlik 11-12).

$M S E=\frac{1}{N} \sum_{i=1}^{N}\left(T_{i}-P_{i}\right)^{2}$

$R=\frac{\sum_{i=1}^{N}\left(\left(T_{i}-\bar{T}\right)\left(P_{i}-\bar{P}\right)\right)}{\sqrt{\sum_{i=1}^{N}\left(T_{i}-\bar{T}\right)^{2} \sum_{i=1}^{N}\left(P_{i}-\bar{P}\right)^{2}}}$

Eşitliklerde yer alan $T_{i}$ i. gerçek değeri, $\bar{T}$ ortalama gerçek değeri, $P_{i}$ i. tahmin edilen değeri, $\bar{P}$ tahmin edilen ortalama değeri ve N örnek büyüklüğünü göstermektedir.

\section{AMAÇLANAN MODEL (PROPOSED MODEL)}

Kan ve kan bileşenlerinin talep tahmininde en büyük zorluk talep edilen ve bağışlanan kan bileşeninin miktar ve zamanlarının belirsiz olmasıdır. Amaçlanan tahmin modelinde öncelikle kan bileşeni olan eritrosit süspansiyonuna ait talep miktarını etkileyen kriterler belirlenmiştir. $\mathrm{Bu}$ kriterlerin sayısı çok olduğu için gruplandırarak azaltmak ve kriterler arasındaki bağımlılıkları ortadan kaldırmak amaciyla PCA 
yönteminden yararlanılmıştır. PCA sonucunda bulunan faktör skorları girdi, tahmin edilen eritrosit süspansiyonu miktarı da çıktı olarak ANFIS modelinde kullanılmıştır. Talep tahmininde ANFIS metodu kullanılmasiyla, niceliksel tahmin yöntemlerinde olmayan veriler arasındaki bilinmeyen veya modellenmesi zor olan ilişkilerin kolayca belirlenip örneklerin eğitilebilmesi, değişen şartlara uyum sağlaması ve eksik verilerde bile çalışabilmesi gibi bazı özelliklerden yararlanılmıştır. Bunun yanı sira, ANFIS modeli tahminleyici kriter sayıs1 az olduğunda işe yarar bir yöntemdir [27-28]. Ayrıca modelin performansını arttırabilmek için ANFIS'in yapısına ve öğrenmesine ait parametre seviyeleri Taguchi yöntemi kullanılarak belirlenmiştir. Amaçlanan modelin akış şeması Şekil 2'de görülmektedir.

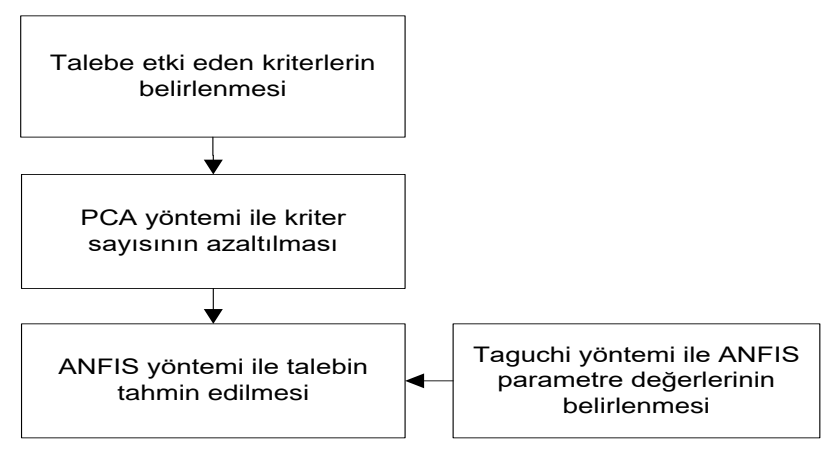

Şekil 2. Amaçlanan hibrit tahmin modeli (Proposed hybrid forecasting model)

\section{UYGULAMA (APPLICATION)}

Modelin uygulanacağı BKM'nin son 5 yıllık kayıtlarından elde edilen kan bileşenlerinin ortalama talep miktarları Tablo 1'de özetlenmiştir. Çalışma kapsamında kan bileşenleri arasından talep miktarı en fazla olan eritrosit süspansiyonu seçilmiştir.

Tablo 1. BKM'den talep edilen kan bileşeni miktarları (ünite) (Amount of blood components requested from Regional Blood Center (unit) )

\begin{tabular}{|l|l|l|l|}
\hline $\begin{array}{l}\text { Eritrosit } \\
\text { Süspansiyonu }\end{array}$ & $\begin{array}{l}\text { Taze } \\
\text { Donmuş } \\
\text { Plazma }\end{array}$ & $\begin{array}{l}\text { Trombosit } \\
\text { Süspansiyonu }\end{array}$ & $\begin{array}{l}\text { Toplam Kan } \\
\text { Bileşeni Miktari }\end{array}$ \\
\hline 74.449 & 33.333 & 15.443 & 123.225 \\
\hline
\end{tabular}

Daha sonra kan bankacılığında TM'lerin talep edeceği eritrosit süspansiyonu miktarına etki eden 15 adet kriter üç uzman görüşü esas alınarak belirlenmiştir (Tablo 2). Çalışmada; $\mathrm{C}_{1}, \mathrm{C}_{2}$ ve $\mathrm{C}_{6}$ kriterleri için önceki haftaya ait değerler, geriye kalan kriterler için ise o güne ait değerler girdi olarak kullanılarak o güne ait talep tahmini yapılması amaçlanmıştır. Belirlenen kriterlere bağlı olarak talep tahmini yapmak için en çok kullanılan yöntemlerden biri olan çoklu doğrusal analizi uygulanmak istendiğinde $\mathrm{R}^{2}$ değeri $\% 93$ olmasına rağmen bağımsız olması istenen kriterler arasında çoklu doğrusal bağlantı sorununu olduğu görülmektedir (Tablo 3). Tablodan da görüldüğü gibi $\mathrm{C}_{3}, \mathrm{C}_{5}, \mathrm{C}_{6}, \mathrm{C}_{7}, \mathrm{C}_{11}$ ve $\mathrm{C}_{14}$ kriterlerinin VIF değerlerinin 10'dan yüksek olması bu kriterlerde ciddi çoklu doğrusal bağlantı olduğunu göstermektedir.

Belirlenen kriterlere bağlı olarak talep tahmini yapmak için en çok kullanılan yöntemlerden biri olan çoklu doğrusal analizi uygulanmak istendiğinde $\mathrm{R}^{2}$ değeri \% 93 olmasına rağmen bağımsız olması istenen kriterler arasında çoklu doğrusal bağlantı sorununu olduğu görülmektedir (Tablo 3). Tablodan da görüldüğü gibi $\mathrm{C}_{3}$, $\mathrm{C}_{5}, \mathrm{C}_{6}, \mathrm{C}_{7}, \mathrm{C}_{11}$ ve $\mathrm{C}_{14}$ kriterlerinin VIF değerlerinin 10 'dan yüksek olması bu kriterlerde ciddi çoklu doğrusal bağlantı olduğunu göstermektedir.

Tablo 2. Eritrosit süspansiyonu talep miktarına miktarına etki eden kriterler (Criteria affecting the amount of red blood cells demand)

\begin{tabular}{|l|l|}
\hline & Talep edilen eritrosit sayısına etki eden kriterler \\
\hline $\mathrm{C}_{1}$ & $\begin{array}{l}\text { Önceki haftaya ait BKM'den karşılanamayan, acil ihtiyaç } \\
\text { nedeni ile TM'nin gerçekleştirdiği kan bağışı sayısı }\end{array}$ \\
\hline $\mathrm{C}_{2}$ & Önceki haftaya ait kan bileşeni talep miktarları \\
\hline $\mathrm{C}_{3}$ & Hastane yatak kapasitesi \\
\hline $\mathrm{C}_{4}$ & $\begin{array}{l}\text { Hastanede kan bileşeni kullanımını arttıran yeni tedavi } \\
\text { uygulamalarının devreye girmesi }\end{array}$ \\
\hline $\mathrm{C}_{5}$ & Toplam muayene sayısı \\
\hline $\mathrm{C}_{6}$ & Önceki haftaya ait acil muayene sayısı \\
\hline $\mathrm{C}_{7}$ & Yatan hasta sayıs1 \\
\hline $\mathrm{C}_{8}$ & Yatak doluluk oranı \\
\hline $\mathrm{C}_{9}$ & Ameliyat sayılları \\
\hline $\mathrm{C}_{10}$ & Hastane rolü (A1, A2, B, C, D) \\
\hline $\mathrm{C}_{11}$ & Hastanenin bulunduğu il/ilçe nüfusu \\
\hline $\mathrm{C}_{12}$ & Resmi tatiller \\
\hline $\mathrm{C}_{13}$ & Organ nakli sayıs1 \\
\hline $\mathrm{C}_{14}$ & Göçmen sayıs1 \\
\hline $\mathrm{C}_{15}$ & Haftalık ortalama sıcaklık değerleri \\
\hline
\end{tabular}

Tablo 3. Kriterlere ait VIF değerleri (VIF values of components)

\begin{tabular}{|l|r|r|r|r|r|}
\hline Terim & Katsay1 & SE Katsay1 & T-Değeri & P-Değeri & VIF \\
\hline Sabit & 37,8000 & 94,100 & 0,400 & 0,688 & \\
\hline $\mathrm{C}_{1}$ & 0,05650 & 0,0355 & 1,590 & 0,112 & 7,590 \\
\hline $\mathrm{C}_{2}$ & 0,08050 & 0,0300 & 2,680 & 0,008 & 6,700 \\
\hline $\mathrm{C}_{3}$ & 0,24070 & 0,0410 & 5,880 & 0,000 & 285,54 \\
\hline $\mathrm{C}_{5}$ & 0,01807 & 0,0022 & 8,210 & 0,000 & 350,32 \\
\hline $\mathrm{C}_{6}$ & $-0,00403$ & 0,0028 & $-1,450$ & 0,148 & 38,430 \\
\hline $\mathrm{C}_{7}$ & $-0,30030$ & 0,0610 & $-4,920$ & 0,000 & 250,71 \\
\hline $\mathrm{C}_{8}$ & 242,600 & 39,700 & 6,110 & 0,000 & 1,860 \\
\hline $\mathrm{C}_{9}$ & $-58,8800$ & 4,8500 & $-12,14$ & 0,000 & 1,850 \\
\hline $\mathrm{C}_{10}$ & 0,00973 & 0,0026 & 3,740 & 0,000 & 4,660 \\
\hline $\mathrm{C}_{11}$ & $-0,00118$ & 0,0003 & $-3,710$ & 0,000 & 338,09 \\
\hline $\mathrm{C}_{12}$ & $-9,09000$ & 2,8600 & $-3,180$ & 0,002 & 1,100 \\
\hline $\mathrm{C}_{14}$ & 0,04926 & 0,0098 & 5,050 & 0,000 & 74,41 \\
\hline $\mathrm{C}_{15}$ & 0,42700 & 0,2320 & 1,840 & 0,066 & 1,220 \\
\hline
\end{tabular}

Çoklu doğrusal bağlantı, bağımsız değişkelerin (kriterler) sadece bağımlı değişken (talep miktarı) üzerinde değil birbiri üzerinde de etkilerinin olduğunu göstermektedir. $\mathrm{Bu}$ nedenle bağlantı sorununu ortadan kaldırmak ve kriter sayısını azaltmak için PCA yönteminden yararlanılmıştır. PCA yönteminde analize başlamadan önce KMO ve Barlett testleri uygulanmıştır. KMO değeri 0.91 ve Barlett testi sonucu da 0.00 (Sig. $=0.00<0.05$ ) olduğundan 
bileşenlerin PCA için uygun olduğu görülmektedir. Tablo 4'de 6 kriterin başlangıç özdeğerinin 1'den büyük olması 15 kriterin 6 bileşene indirgendiğini göstermektedir. PCA yöntemi sonucunda elde edilen bileşenler, modelin toplam varyansının \% 82.283'ünü açıklayabilmektedir (Tablo 4).

Tablo 4. Özdeğerler ve toplam varyans yüzdesi değerleri (Eigenvalues and total variance percentage values)

\begin{tabular}{|l|l|l|l|l|l|l|}
\hline Kriterler & \multicolumn{3}{|l|}{ Başlangıc̈zdeğerler } & \multicolumn{3}{|l|}{ Varyans AçıklamaYüzdesi } \\
\hline & Toplam & Var\% & Cum \% & Toplam & Var\% & Küm. \% \\
\hline $\mathrm{C}_{1}$ & 4.316 & 28.775 & 28.775 & 4.316 & 28.775 & 28.775 \\
\hline $\mathrm{C}_{2}$ & 2.280 & 15.202 & 43.978 & 2.280 & 15.202 & 43.978 \\
\hline $\mathrm{C}_{3}$ & 1.985 & 13.234 & 57.212 & 1.985 & 13.234 & 57.212 \\
\hline $\mathrm{C}_{4}$ & 1.454 & 9.6910 & 66.903 & 1.454 & 9.6910 & 66.903 \\
\hline $\mathrm{C}_{5}$ & 1.266 & 8.4390 & 75.342 & 1.266 & 8.4390 & 75.342 \\
\hline $\mathrm{C}_{6}$ & 1.041 & 6.9410 & 82.283 & 1.041 & 6.9410 & 82.283 \\
\hline $\mathrm{C}_{7}$ & .9780 & 6.5210 & 88.805 & & & \\
\hline $\mathrm{C}_{8}$ & .7230 & 4.8170 & 93.622 & & & \\
\hline $\mathrm{C}_{9}$ & .5150 & 3.4360 & 97.058 & & & \\
\hline $\mathrm{C}_{10}$ & .2990 & 1.9940 & 99.052 & & & \\
\hline $\mathrm{C}_{11}$ & .0760 & .50700 & 99.559 & & & \\
\hline $\mathrm{C}_{12}$ & .0610 & .40800 & 99.967 & & & \\
\hline $\mathrm{C}_{13}$ & .0040 & .02700 & 99.994 & & & \\
\hline $\mathrm{C}_{14}$ & .0010 & .00600 & 100.00 & & & \\
\hline $\mathrm{C}_{15}$ & $2.5 \mathrm{E}-16$ & $1.72 \mathrm{E}-15$ & 100.00 & & & \\
\hline
\end{tabular}

Tabloya 4'e göre; birinci bileşen toplam varyansın \% 28.775 'ini, ikinci bileșen toplam varyansın $\%$ 15.202'sini, üçüncü bileşen toplam varyansın \% 13.234'ünü, dördüncü bileşen toplam varyansın \% 9.6910'sını, beşinci bileşen toplam varyansın \% 8.4390'ını, altıncı bileşen ise toplam varyansın \% 6.9410'unu açıklamaktadır. Tablo 5'de ise kriterlerin atandığı bileşenler belirlenmiştir. 1. bileşende $\mathrm{C}_{1}, \mathrm{C}_{2}, \mathrm{C}_{5}$, $\mathrm{C}_{6}$ ve $\mathrm{C}_{7}$ kriterleri $0.801,0.779,0.929,0.894,0.910$ yükleri ile; 2 . bileşende $C_{3}$ ve $C_{11}$ kriterleri $0.896,0.934$ yükleri ile; 3 . bileşende $C_{4}$ ve $C_{13}$ kriterleri $0.943,0.934$ yükleri ile; 4 . bileşende $\mathrm{C}_{14}$ ve $\mathrm{C}_{8}$ kriterleri 0.865 , -0.544 yükleri ile; 5 . bileşende $C_{9}$ kriteri 0.616 yükü ile ve 6 . bileşende $C_{12}$ ve $C_{15}$ kriterleri -0.605 ve -0.515 yükleri ile yer almaktadır. Bileşenlerde yer alan negatif değerler o kriterin, aynı bileşen içinde yer alan diğer kriterlerle negatif ilişkisinin olduğunu göstermektedir. $\mathrm{C}_{10}$ kriteri ise yük değerleri 0.5 'den az ve yükler arasındaki fark 0.1 'den küçük olduğu için analizden çıkarılmıştır [29].

PCA sonunda elde edilen faktör yükleri ANFIS'in girdilerini, TM'nin talep ettiği eritrosit süspansiyonu miktarları da ANFIS'in çıktısını oluşturmaktadır. Modelde BKM'nin toplam talebinin yaklaşık \%80'ini oluşturan 12 TM'ye ait 520 haftalık verinin \%70'ine karşılık gelen 364 haftalık veri eğitim için kullanılmıştır. Geriye kalan \%30'luk k1smı olan 156 haftalık veri ise test için ayrılmıştır. ANFIS'in doğruluğu; yapılarını ve öğrenmelerini etkileyen parametrelerin doğru belirlenmesi ile ilişkilidir [30]. Literatürde yapılan çalışmaların çoğunda [21-35], bu parametreler rastgele veya deneme yanılma yöntemiyle seçilmiştir. Ancak bu durumda daha iyi sonuç verecek parametre kombinasyonunun belirlenememesi söz konusudur. Diğer taraftan parametre kombinasyonlarının tek tek denenmesi de hem işlem karmaşasına hem de zaman kaybına neden olacaktır. Bu nedenle uygulamada, Taguchi yöntemi kullanılarak gerçekleşen ve tahmin edilen talepler arasındaki farkı minimize eden MSE ile en iyi performansı gösteren kombinasyon belirlenmiştir.

Tablo 5. Kriterlere ait yükler (Loads of criteria)

\begin{tabular}{|c|r|r|r|r|r|r|}
\hline \multirow{2}{*}{ Kriter } & \multicolumn{7}{|c|}{ Kriterlere ait yükler } \\
\cline { 2 - 7 } & 1 & \multicolumn{1}{|c|}{2} & \multicolumn{1}{c|}{3} & \multicolumn{1}{c|}{4} & \multicolumn{1}{c|}{5} & \multicolumn{1}{c|}{6} \\
\hline 1 & $\mathbf{. 8 0}$ & .07 & -.02 & -.04 & .29 & -.01 \\
\hline 2 & $\mathbf{. 7 8}$ & .19 & .00 & -.16 & .11 & -.04 \\
\hline 5 & $\mathbf{. 9 3}$ & -.10 & .03 & .16 & -.01 & .19 \\
\hline 6 & $\mathbf{. 8 9}$ & -.19 & .05 & .22 & .06 & .21 \\
\hline 7 & $\mathbf{9 1}$ & .05 & -.02 & .15 & -.09 & .17 \\
\hline 3 & -.01 &. $\mathbf{9 0}$ & -.22 & -.31 & .02 & .02 \\
\hline 11 & -.06 & $\mathbf{. 9 3}$ & -.27 & .11 & .06 & .02 \\
\hline 4 & -.03 & .32 &. $\mathbf{9 4}$ & .05 & .06 & -.00 \\
\hline 13 & -.03 & .32 &. $\mathbf{9 4}$ & .05 & .06 & -.00 \\
\hline 14 & -.16 & .12 & -.10 & $\mathbf{. 8 7}$ & .12 & -.03 \\
\hline 8 & -.11 & -.17 & .04 & -.54 & .53 & .44 \\
\hline 9 & -.34 & .26 & -.21 & .33 & $\mathbf{. 6 2}$ & .32 \\
\hline 12 & .24 & .01 & -.04 & .06 & .31 & -.61 \\
\hline 15 & .34 & -.07 & -.05 & -.19 & .44 & -.52 \\
\hline 10 & .49 & .45 & -.13 & -.16 & -.44 & .01 \\
\hline
\end{tabular}

Tablo 6. ANFIS $\mathrm{L}_{16}$ deney tasarımı ve deney sonuçları (ANFIS $\mathrm{L}_{16}$ test design and test results)

\begin{tabular}{|l|l|l|l|l|l|l|c|}
\hline & A & B & C & D & E & F & Test hatas1 \\
\hline 1 & trimf & 3 & Constant & 100 & BP & 0.0 & 0.188 \\
\hline 2 & trimf & 5 & Linear & 300 & Hybrid & 0.1 & 9.176 \\
\hline 3 & trapmf & 3 & Constant & 100 & BP & 0.1 & 0.195 \\
\hline 4 & trapmf & 5 & Linear & 300 & Hybrid & 0.0 & 9.320 \\
\hline 5 & gbellmf & 3 & Constant & 300 & Hybrid & 0.0 & 2.434 \\
\hline 6 & gbellmf & 5 & Linear & 100 & BP & 0.1 & 0.217 \\
\hline 7 & gaussmf & 3 & Constant & 300 & Hybrid & 0.1 & 5.998 \\
\hline 8 & gasssmf & 5 & Linear & 100 & BP & 0.0 & 0.261 \\
\hline 9 & gauss2mf & 3 & Linear & 100 & Hybrid & 0.0 & 1.129 \\
\hline 10 & gauss2mf & 5 & Constant & 300 & BP & 0.1 & 0.259 \\
\hline 11 & pimf & 3 & Linear & 100 & Hybrid & 0.1 & 4.512 \\
\hline 12 & pimf & 5 & Constant & 300 & BP & 0.0 & 0.195 \\
\hline 13 & dsigmf & 3 & Linear & 300 & BP & 0.0 & 0.208 \\
\hline 14 & dsigmf & 5 & Constant & 100 & Hybrid & 0.1 & 14.88 \\
\hline 15 & psigmf & 3 & Linear & 300 & BP & 0.1 & 0.208 \\
\hline 16 & psigmf & 5 & Constant & 100 & Hybrid & 0.0 & 6.755 \\
\hline
\end{tabular}

BP: Geri yayılım

ANFIS parametreleri; literatürde yer alan [30, 36-39] tarafından gerçekleştirilen çalışmalar temel alınarak belirlenmiştir. Uygulamada girdi üyelik tipi (A) seviyesi 8 ve diğerler parametreler (girdi üyelik fonksiyonu sayısı (B), çıktı üyelik fonksiyonu tipi (C), iterasyon sayısı (D), optimizasyon metodu (E) ve hata oranı (F)) 2 seviyede ele alınmıştır. Belirlenen seviyelere uygun olarak $\mathrm{L}_{16}$ mixed Taguchi deney tasarımı çalıştırılmıştır. ANFIS eğitiminde; ortalama hata değeri, eğitim hata değeri ve test hata değeri hesaplanmaktadır. Uygulamada sadece test hatası değerleri deney sonucu olarak alınmıştır (Tablo 6). Çünkü ANFIS eğitiminde önemli olan gelecekte meydana gelecek talep miktarlarını en az hatayla tahmin etmektir [40]. Model üzerinde etkili olan 
parametrelerin belirlenmesi için ANOVA testi uygulanmıştır. Sonuç olarak \% 5 anlam düzeyinde $\mathrm{C}$ ve $\mathrm{E}$ parametreleri model üzerinde etkili çıkmıştır (Tablo 7). $\mathrm{Bu}$ nedenle çıktı üyelik fonksiyonu tipi linear $\left(\mathrm{C}_{2}\right)$ ve optimizasyon metodu geri yayılım $\left(\mathrm{E}_{1}\right)$ olarak belirlenmiştir.

Tablo 7. ANOVA testi sonucu (ANOVA test result)

\begin{tabular}{|c|c|c|l|l|c|c|}
\hline Kaynak & SD & Seq SS & Adj SS & Adj MS & F-Değeri & P-Değeri \\
\hline A & 7 & 151.42 & 151.42 & 21.630 & 2.600 & 0.233 \\
\hline B & 1 & 3.6900 & 3.6900 & 3.6900 & 0.440 & 0.553 \\
\hline C & 1 & 136.27 & 136.27 & 136.27 & 16.37 & 0.027 \\
\hline D & 1 & 4.5300 & 4.5300 & 4.5300 & 0.540 & 0.514 \\
\hline E & 1 & 3116.4 & 3116.4 & 3116.4 & 374.4 & 0.000 \\
\hline F & 1 & 49.240 & 49.240 & 49.240 & 5.920 & 0.093 \\
\hline Hata & 3 & 24.970 & 24.970 & 8.3200 & & \\
\hline Toplam & 15 & 3486.5 & 3486.5 & & & \\
\hline
\end{tabular}

SD: Serbestlik derecesi

A, B, D ve F faktörleri ise etkisiz olduğu için herhangi bir seviyede olabilir ancak Şekil 3'den de görüldüğü gibi optimum sonucu veren parametre seviyeleri $\mathrm{A}_{5} \mathrm{~B}_{1} \mathrm{C}_{2} \mathrm{D}_{1} \mathrm{E}_{1} \mathrm{~F}_{1}$ olarak ele alınmıştır. Bu durumda $\mathrm{A}, \mathrm{B}, \mathrm{D}$ ve $F$ faktör seviyeleri sirasıyla gauss $2 \mathrm{mf}, 3,100$ ve 0.0 şeklinde belirlenmiştir.

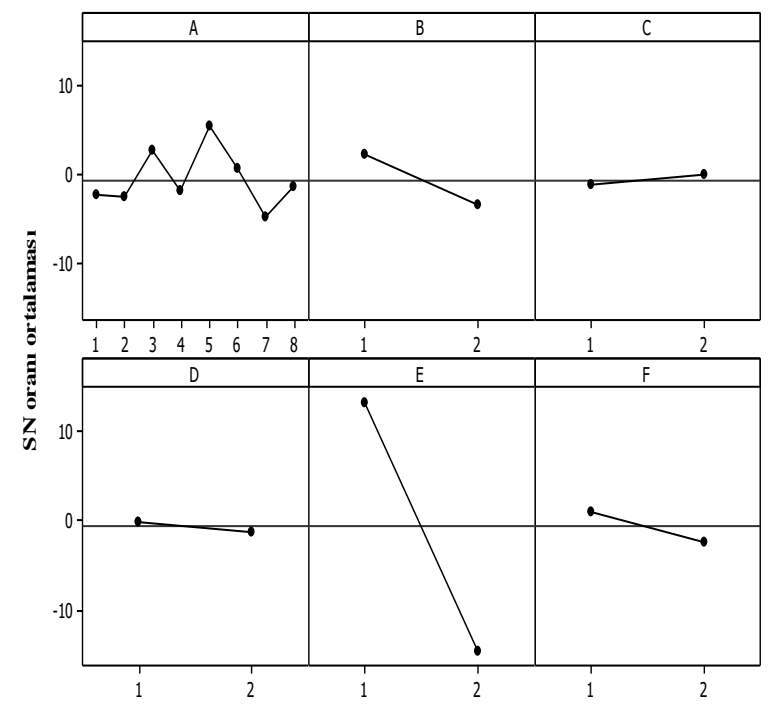

Şekil 3. Parametre seviyelerinin ortalama S/N oranları (Average $\mathrm{S} / \mathrm{N}$ ratios of parameter levels)

Bulunan optimum kombinasyon ANFIS'de test edilince elde edilen ortalama hata, eğitim ve test hata değerleri sırasıyla $0.147,0.147$ ve 0.165 olarak bulunmuştur. Bulunan test hatası değerinin Tablo 6'da Taguchi deney tasarımında kullanılan test hatası değerlerinden düşük olduğu için optimum kombinasyonun bulunduğu söylenebilir.

Çalışmada uygulanan PCA esaslı hibrit ANFIS-Taguchi yönteminin performansını ölçebilmek için $\mathrm{R}$ istatistiksel performans kriteri kullanılmıştır. R değeri 0.881 olarak hesaplanmıştır. Bu da önerilen PCA esaslı hibrit ANFISTaguchi yönteminin uygun tahminlerde bulunduğu göstermektedir [41].

Uygulamada eritrosit süspansiyonu talep miktarının en az hata ile tahmin edilmesi amaçlanmaktadır. $\mathrm{Bu}$ nedenle talep edilen ve tahmin edilen eritrosit süspansiyonu miktarının arasındaki farkın en aza indirilmesi istenmektedir. Şekil 4'de haftalar bazında tahmin hataları görülmektedir. $x$ ekseninde yer alan ' 0 ' noktası talep edilen ve tahmin edilen eritrosit süspansiyonunun eşit olduğunu göstermektedir. $\mathrm{Bu}$ eksende yer alan negatif değerler bir hafta boyunca ele alınan TM'lerde hafta içerisinde eksik tahmin edilen eritrosit süspansiyonu miktarını, pozitif değerler ise bir hafta boyunca ele alınan TM'lerde fazla tahmin edilen eritrosit süspansiyonu miktarını göstermektedir. Örnek olarak 1. haftayı baz alırsak; $\mathrm{C}_{1}$ kriter değeri 92, $\mathrm{C}_{2}$ kriter değeri $219, \mathrm{C}_{3}$ kriter değeri 3363, $\mathrm{C}_{4}$ kriter değeri $0, \mathrm{C}_{5}$ kriter değeri $38508, \mathrm{C}_{6}$ kriter değeri 8986, $\mathrm{C}_{7}$ kriter değeri $1334, \mathrm{C}_{8}$ kriter değeri $0.69, \mathrm{C}_{9}$ kriter değeri $4772, \mathrm{C}_{10}$ kriter değeri $1, \mathrm{C}_{11}$ kriter değeri 844842, $\mathrm{C}_{12}$ kriter değeri $0, \mathrm{C}_{13}$ kriter değeri $0, \mathrm{C}_{14}$ kriter değeri 2082 ve $\mathrm{C}_{15}$ kriter değeri 21.4 olduğunda gerçekleşen eritrosit süspansiyonu talep miktarı 399 iken; tahmin edilen eritrosit süspansiyonu talep miktarı 332 olarak belirlenmiştir. Yani eritrosit süspansiyonu tahmin hatasının -67 olduğu görülmektedir.

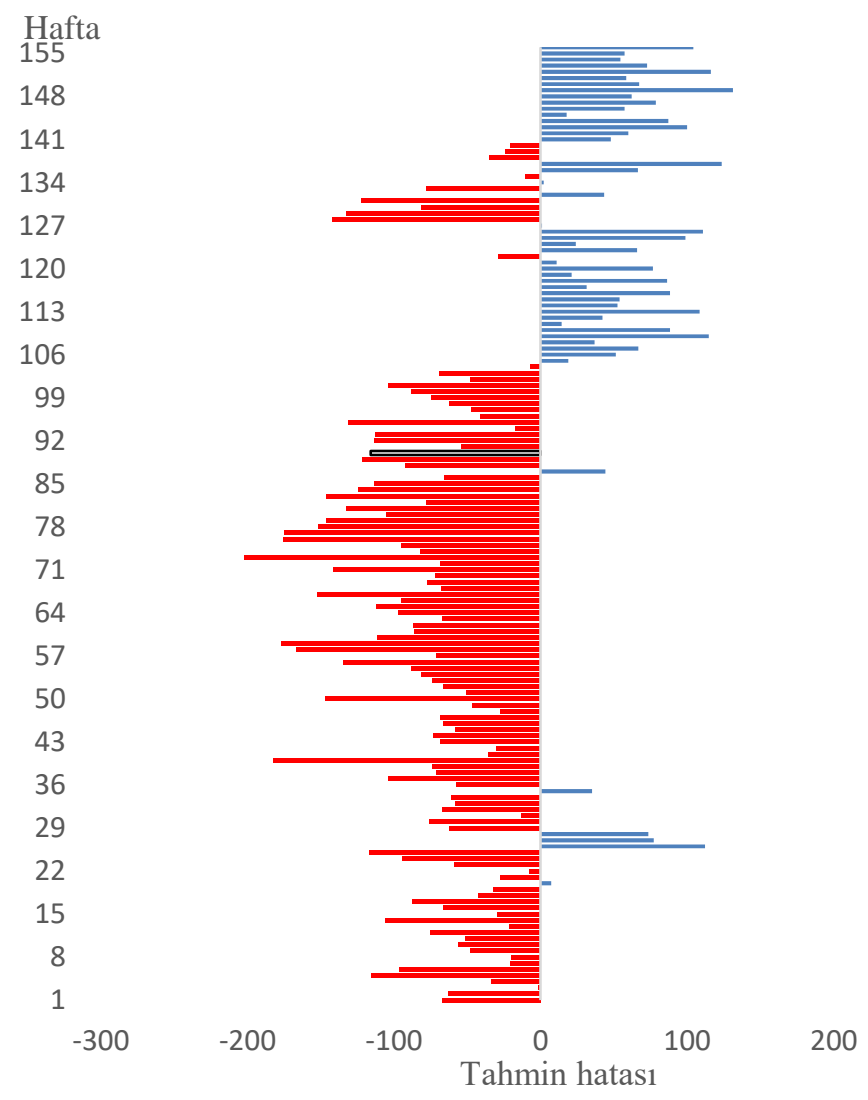

Şekil 4. Haftalara bağlı tahmin hataları (ünite) (Forecast errors according to weeks (unit) ) 
Uygulamada, PCA yönteminin adımları için SPSS 16.0, ANFIS yöntemi adımları için MATLAB R2014A ve Taguchi yöntemi adımları için ise MINITAB16 programları kullanılmıştır.

\section{SONUÇ VE ÖNERİLER (RESULT AND DISCUSSIONS)}

Literatürde kan bileşenlerine ait talep tahmin problemlerinde; yaş, kan grubu ve cinsiyet gibi az sayıda değişken ile tahminlerde bulunulmuştur. Ancak kan bileşeni talebi diş ortamdan etkilenen dinamik bir süreçtir. $\mathrm{Bu}$ nedenle çalışmada literatürdeki çalışmalardan farklı olarak 15 farklı kriter belirlenmiştir. Bunun yanı sıra literatürde, niceliksel tahmin yöntemleri ve özellikle ANN'nin kullanıldığı yapay zeka tabanlı tahmin yöntemleri ile kan talebi tahmini çalışmaları da vardır. Bu çalışmada ise tahmin problemlerinde daha iyi sonuçlar veren ve az sayıda girdi ile de çalışabilen ANFIS yöntemi ile eritrosit süspansiyonu talep miktarı tahmin edilmiştir. Talebe etki eden kriter sayısı çok olduğu için gruplandırarak azaltmak amaciyla temel bileşen analizi kullanılmıştır. Böylece modelin karmaşıklığını azaltılması ve kullanılabilirliğinin arttırılması amaçlanmıştır. Uygulamada kullanılan ANFIS yönteminin eleştirilen özelliği model yapısının ve öğrenmesi ile ilgili parametrelerin optimum değerlerinin belirlenmesinin zaman alıcı olması da Taguchi yönteminden yararlanılarak aşılmıştır. Taguchi yönteminde kullanılacak olan parametrelerden yapısal olanlar girdi üyelik tipi gauss2 mf, girdi üyelik fonksiyonu sayısı 3, çıktı üyelik fonksiyonu tipi lineer; öğreneme ile ilgili parametreler ise iterasyon sayısı 100, optimizasyon metodu geri yayılım, hata oranı 0.0 olarak belirlenmiştir.

Uygulama sonunda modelin performansını ve doğru tahmin etme kabiliyetini değerlendirmek amaciyla kullanılan $\mathrm{R}$ performans ölçütü değeri 0.881 olarak hesaplanmıştır. $\mathrm{Bu}$ da modelin talep tahmininde kullanılmak için uygun olduğunu göstermektedir.

Model benzer koşullara sahip diğer kan merkezleri için de kullanılabilir özelliğe sahiptir. Bunun yanı sıra model, trombosit süspansiyonu ve taze donmuş plazma gibi diğer kan bileşenlerinin talep tahmininde de uygulanabilir.

Gelecekteki çalışmalarda ANFIS metodu yerine farklı makine öğrenme algoritmalarının kullanılması planlanmaktır.

\section{KAYNAKLAR (REFERENCES)}

[1] T. Akita, J. Tanaka, M. Ohisa, A. Sugiyama, K. Nishida, S. Inoue, T. Shirasaka, "Predicting future blood supply and demand in Japan with a Markov model: application to the sex- and agespecific probability of blood donation", Transfusion, 56(11), 2750-2759, 2016.

[2] E.H.Y. Lau, X.Q. He, C.K. Lee, J T. Wu, "Predicting future blood demand from thalassemia major patients in Hong Kong", PLoS ONE, 8(12), e81846, 2013.
[3] C.J. Currie , T.C. Patel , P. McEwan , S. Dixon, "Evaluation of the future supply and demand for blood products in the United Kingdom National Health Service", Transfus Med, 14(1), 19-24, 2004.

[4] D.M.S. Kumari, A. N. Wijayanayake, "An efficient inventory model to reduce the wastage of blood in the national blood transfusion service" 2016 Manufacturing \& Industrial Engineering Symposium (MIES), Colombo, 1-4, 2016.

[5] A. Wijayanayake, M. Dandunna, "An efficient model to improve the performance of platelet inventory of the blood banks", $A d v$ Sci Technol Eng Syst J, 2(3), 839-844, 2017.

[6] A. Drackley , K.B. Newbold , A. Paez , N. Heddle, "Forecasting Ontario's blood supply and demand", Transfusion, 52(2), 366374,2012

[7] A. Pereira, "Performance of time-series methods in forecasting the demand for red blood cell transfusion", Transfusion, 44(5), 739-746, 2004.

[8] F,Firouzi Jahantigh, B. Fanoodi, S. Khosravi, "A demand forcasting model for the blood platelet supply chain with Artificial Neural Network approach and ARIMA models", Sci J Iran Blood Transfus Organ, 14(4), 335-345, 2018.

[9] S. Walczak, J.E. Scharf, "Reducing surgical patient costs through use of an artificial neural network to predict transfusion requirements", Decis Support Syst, 30(2), 125-138, 2000.

[10] W.H. Ho, C.S. Chang, "Genetic-algorithm-based artificial neural network modeling for platelet transfusion requirements on acute myeloblastic leukemia patients", Expert Syst Appl, 38(5), 63196323, 2011.

[11] S. Haghani, Sedehi M, Kheiri S, "Artificial neural network to modeling zero-inflated count data: application to predicting number of return to blood donation", J Res Health Sci, 17(3), e00392, 2017.

[12] H. Shih, S. Rajendran, "Comparison of Time Series Methods and Machine Learning Algorithms for Forecasting Taiwan Blood Services Foundation's Blood Supply", J Healthc Eng, 2019, Article ID 6123745, 2019.

[13] S. Barak, J.H. Dahooie, T. Tichý, "Wrapper ANFIS-ICA method to do stock market timing and feature selection on the basis of Japanese Candlestick", Expert Syst Appl,42(23), 9221-9235, 2015.

[14] A. Dariane, S. Azimi, "Forecasting streamflow by combination of genetic input selection algorithm and wavelet transforms using ANFIS model", Hydrol Sci J, 61(3), 585-600, 2016.

[15] A. K. Sangaiah, A. K. Thangavelu, X. Z. Gao, N. Anbazhagan, M. S. Durai, "An ANFIS approach for evaluation of team-level service climate in GSD projects using Taguchi-genetic learning algorithm", Appl Soft Comput, 30, 628-635, 2015.

[16] A. Sarkheyli, A. MohdZain, S. Sharif, "Robust optimization of ANFIS based on a new modified GA", Neurocomputing, 166, 357-366, 2015

[17] R. Bro, A.K. Smilde, "Principal component analysis", Anal Methods, 6(9), 2812-2831, 2014. 
[18] J.A.M. Bispo, E. E. de Sousa Vieira, L. Silveira, A.B. Fernandes, "Correlating the amount of urea, creatinine, and glucose in urine from patients with diabetes mellitus and hypertension with the risk of developing renal lesions by means of Raman spectroscopy and principal component analysis", $J$ Biomed Opt, 18(8), 2013.

[19] T. Ş. Yapraklı, H. Erdal, "Firma Başarısızlığı Tahminlemesi: Makine Öğrenmesine Dayalı Bir Uygulama", Bilişim Teknolojileri Dergisi, 9(1), 21-31, 2016.

[20] O.A. Oral, Ö.Ö. Tanrı̈ver, M. Soubra, "Modeling and Predicting Scientific Thinking Skills of University Students Using a Data Mining Tool”, Bilişim Teknolojileri Dergisi, 10(1), 89-95, 2017.

[21] D.H. Vu, K.M. Muttaqi, A.P. Agalgaonkar, "A variance inflation factor and backward elimination based robust regression model for forecasting monthly electricity demand using climatic variables", Appl Energy, 140, 385-394, 2015.

[22] A. C. Hadjichambis, D. Paraskeva-Hadjichambi, "Environmental Citizenship Questionnaire (ECQ): The Development and Validation of an Evaluation Instrument for Secondary School Students", Sustainability, 12(3), 821-833, 2020.

[23] D. Wang, L. Shi, "Source identification of mine water inrush: a discussion on the application of hydrochemical method", Arab $J$ Geosci, 12(58), 2019.

[24] J. Jang, "ANFIS: adaptive-network-based fuzzy inference system”, Ieee Trans Syst Man Cybern Syst, 23(3), 665-685, 1993.

[25] M. Şahin, R. Erol, "A comparative study of neural networks and ANFIS for forecasting attendance rate of soccer games", Math Comput Appl, 22(43), 12, 2017.

[26] P.J.Ross, Taguchi for Quality Engineering, Mc Graw Hill, second Edution, Newyork, ABD 1996.

[27] M. Milovančević, V. Nikolić, B. Anđelković, "Analyses of the most influential factors for vibration monitoring of planetary power transmissions in pellet mills by adaptive neuro-fuzzy technique", Mech Syst Signal Pr, 82, 356-375, 2017.

[28] F. Mekanik, M. A. Imteaz, A. Talei, "Seasonal rainfall forecasting by adaptive network-based fuzzy inference system (ANFIS) using large scale climate signals", Clim Dyn, 46, 3097$3111,2016$.

[29] Ö. Çokluk, G. Şekercioğlu, Ş. Büyüköztürk, Sosyal Bilimler İçin Çok Değişkenli İstatistik: SPSS ve Lisrel Uygulamaları, Pegem Akademi Yayıncılık, 2012.
[30] S. Boran, S.H. Gökler, "A Novel FMEA Model Using Hybrid ANFIS-Taguchi Method”, Arab J Sci Eng, 45, 2131-2144, 2020.

[31] Riahi-Madvar, H., Seifi, A. "Uncertainty analysis in bed load transport prediction of gravel bed rivers by ANN and ANFIS”. Arab J Geosci, 11, 688, 2018.

[32] H. Baseri, M. Belali-Owsia, "A novel hybrid ICA-ANFIS model for prediction of manufacturing processes performance", $P$ I Mech Eng E-J Pro, 231(2), 181-190, 2017.

[33] M. Ganjeh, S. M. Jafari, M. Amanjani, I. Katouzian, "Modeling corrosion trends in tin-free steel and tinplate cans containing tomato paste via adaptive-network-based fuzzy inference system”, J Food Process Eng., 40, e12580, 2017.

[34] M. H. Jokar, A. Khosravi, A. Heidaripanah, F. Soltani, "Unsaturated soils permeability estimation by adaptive neurofuzzy inference system”, Soft Comput, 23 (16), 6871-6881, 2019.

[35] H. Rahnema, M. Hashemi, H. Khabbaz, "Predicting the Effective Stress Parameter of Unsaturated Soils Using Adaptive NeuroFuzzy Inference System", SCI IRA Transactions A: Civil Engineering, 26, 3140-3158, 2019.

[36] F. H. Ismail, M. A. Aziz, A. E. Hassanien, "Optimizing the parameters of Sugeno based adaptive neuro fuzzy using artificial bee colony: A Case study on predicting the wind speed", Proceedings of the Federated Conference on Computer Science and Information Systems, 8, 645-651, 2015.

[37] V. Moosavi, M. Vafakhah, B. Shirmohammadi , M. Ranjbar, "Optimization of Wavelet-ANFIS and Wavelet-YSA hybrid models by Taguchi method for groundwater level", Arab J Sci Eng, 39(3), 1785-1796, 2014.

[38] N. G. Fragiadakis, V. D. Tsoukalas, V. J. Papazoglou, “An adaptive neuro-fuzzy inference system (ANFIS) model for assessing occupational risk in the shipbuilding industry", Saf Sci, 63, 226-235, 2014.

[39] M. Alizadeh, M. Lewis, M. H. F. Zarandi, F. Jolai, "Determining significant parameters in the design of ANFIS", 2011 Annual Meeting of the North American Fuzzy Information Processing Society, 18-20 March 2011 El Paso, TX, USA.

[40] W. Phootrakornchai, S. Jiriwibhakorn, "Online critical clearing time estimation using an adaptive neuro-fuzzy inference system (ANFIS)", Int J Elec Power, 73, 170-181, 2015.

[41] N. Meghanathan, "Assortativity Analysis of Real-World Network Graphs based on Centrality Metrics", Comput Inf Sci, 9(3), 2016. 